\title{
O ENUNCIADO E A POLIFONIA EM BAKHTIN *
}

\section{Ana Maria Gama Florencio ${ }^{(*)}$}

Resumo: Bakhtin inaugura iam nova perspectiva dos estudos de linguagem, ao pensá-la em constante movimento, inacabada, dependente de uma relação dialógica que acontece entre enunciados de diferentes sujeitos falantes (o outro), como parte constitutiva do sujeito e do sentido. Essas "outras vozes", presentes no enunciado, apontam para o diálogo como constitutivo da linguagem e do discurso, deixando-se à mostra pela polifonia ou mascarando-se no fenômeno do dialogismo. Essa é, então, uma visão de sujeito produtor de discursos ideologicamente constituídos, que antecipa a participação da história e da memória na produção de sentidos.

Palavras-chave: Enunciado; dialogismo; polifonia; vozes; história; sujeito; sentido

A teoria bakhtiniana se marca, especificamente, pelas relações com o outro, por um princípio dialógico, por uma concepção de linguagem que inclui a história e o sujeito, por ser a alteridade imprescindível na definição do ser social. Embora seus estudos dialógicos tenham se dirigido à estética da linguagem de Rabelais e Dostoiévski, Bakhtin não se deteve apenas no discurso literário. Sua análise estendeu-se ao discurso do cotidiano, como posto de observação das relações entre o mundo e o homem habitado pelo signo e ideologicamente marcado pelas estruturas sociais: seres socialmente organizados interagem e produzem a enunciação, sempre a partir do prisma do meio social que engloba os interlocutores. A partir de então, abre-se uma nova perspectiva para os estudos da linguagem humana no percurso livre da imprevisibilidade, o que torna o diálogo indispensável e permanente. Daí, o papel da linguagem se modifica e esta passa a ser pensada em suas "múltiplas mediações na interpretação e constituição do sujeito, da cultura e da temporalidade" (JOBIM E SOUZA, 1997, p.338).

Texto apresentado no I Seminário sobre Bakhtin, na Pós-Graduação em

Letras e Linguística da Ufal, em fev. 2002.

(") Professora da Universidade Federal de Algoas. 
Para Bakhtin (1992, p.378), a consciência do homem é despertada pelo outro, pela palavra alheia:

Tomo consciência de mim, originalmente, através dos outros: deles recebo a palavra, a forma e o tom servirão para a formação original da representação que terei de mim mesmo.

Nesse sentido, o sujeito traz em si todas as vozes que o antecederam, um mundo que já foi articulado, compreendido diferentemente. A linguagem está sempre em movimento, sempre inacabada, suscetível de renovação, pela dependência da compreensão que acontece no intervalo do diálogo, onde se constitui a singularidade, pelo fato de a intersubjetividade ser anterior à subjetividade e de a relação entre os interlocutores ser responsável pela construção dos sujeitos produtores de sentido. Mas, para Bakhtin, compreender implica juízo de valor. A compreensão, apesar de já ser detentora de um ponto de vista, é submetida à ação do diálogo. Ou seja, no diálogo há sempre um movimento de ida e vinda que cria a possibilidade de modificação recíproca. Portanto, o dialogismo vem estabelecer uma transformação na visão de sujeito e de linguagem, submetidos às pressões sociais e ideológicas.

Ainda citando Bakhtin, é pela expressão que se organiza sua atividade mental. Qualquer que seja o aspecto da expressãoenunciação, ele será determinado pelas condições reais dessa enunciação, melhor dizendo, pela situação social mais imediata, determinante do grau de consciência dos interlocutores. Assim, é que, para Bakhtin, o pensamento não existe fora de sua expressão potencial, consequientemente, da orientação social dessa expressão. $\mathrm{O}$ percurso que se dá entre a atividade mental (conteúdo a exprimir) e sua objetivação externa (a enunciação) situa-se completamente em território social, na interação verbal entre os interlocutores (enunciador/enunciatário) e aponta, assim, para um sujeito histórica e ideologicamente constituído, habitado por diferentes vozes sociais. Desse modo, a enunciação não prescinde da interação por não se situar em um único enunciador, porque sempre "pressupõe enunciados que a precederam e que a sucederão" (BAKHTIN, 1992, p.375). Não é começo, nem fim, mas sempre elemento de ligação de uma cadeia ininterrupta. 
Ducrot (1984, p.179), refere-se à enunciação como "o acontecimento constituído pela aparição de um enunciado", este último como reflexo do ato de enunciação, de valor ilocutório. Podese, então, pensar a enunciação como ato, o ponto de intersecção entre a língua e o mundo e o enunciado como o produto, lugar de representação da enunciação, ou seja, de um fato, de um acontecimento, definido no tempo e no espaço. Em resumo:

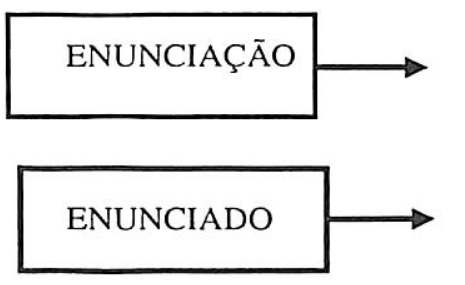

ENCONTRO ENTRE A LÍNGUA
E O ACONTECIMENTO

PRODUTO, LUGAR DE REPRESENTAÇÃO DO ACONTECIMENTO

Para definir o caráter genérico do enunciado Bakhtin (1992, p.293) recorre aos gêneros do discurso, embora reconheça serem estes de constituição "extremamente heterogênea". Classifica-os em primários (simples) e secundários (complexos), como discursos do cotidiano e de comunicação cultural, respectivamente. Os discursos secundários se constituem na absorção e transmutação de gêneros primários que se deram em situações de comunicação verbal espontânea. Esses gêneros primários, ao passarem por essa transformação, se integram ao gênero secundário, perdendo o seu significado cotidiano, para significar somente no discurso complexo, como um todo. Um exemplo disso seria a réplica de um diálogo cotidiano ou uma carta, inseridos no romance. Este gênero (o romance) em seu todo, é, então, um enunciado da mesma forma que as falas de um diálogo do cotidiano ou a carta informal. $O$ que faz a diferença entre eles é a complexidade que se dá, em seu bojo, constituída pela inserção de gêneros simples.

A distinção entre esses gêneros, considerada por Bakhtin de relevante importância teórica, já é antecipada, quando esse autor trata de tema e significação, como próprios às sociedades, sempre em acordo com tipos de composição, estilo e situações. Para ele, a natureza do enunciado - de caráter complexo e sutil - só pode ser entendida na análise dos gêneros, visto que somente assim se torna possível interrelacionar os gêneros primários e secuntários, bem como 
o processo histórico de formação dos gêneros secundários, sem que se abandone a correlação língua/ideologia.

O enunciado é pensado como "unidade real e forma clássica da comunicação verbal" (op. cit.). Bakhtin aponta-lhe características estruturais próprias, como o fato de pertencer a um sujeito falante, não poder existir de outra forma e, principalmente, apresentar fronteiras muito bem delineadas e determinadas pela alternância de sujeitos falantes (locutores). As fronteiras são consideradas por ele como princípio essencial sobre o qual se deve refletir com maior zelo, pois são elas que determinam o começo e o fim de cada enunciado, como unidade real, em que o locutor parte do enunciado do outro e encerra o seu enunciado quando passa a palavra ao outro, dando lugar à compreensão responsiva ativa do outro. Nos gêneros secundários do discurso, particularmente nos gêneros retóricos, em que o locutor parece dar lugar a uma outra fala, as fronteiras não se apresentam marcadas, mas, na verdade, elas existem, tanto quanto nos gêneros primários, deixando-se ver no jogo característico de formulação de perguntas/ respostas às mesmas, refutações a seus próprios argumentos, como uma simulação da comunicação verbal. Desse modo, podemos pensar os

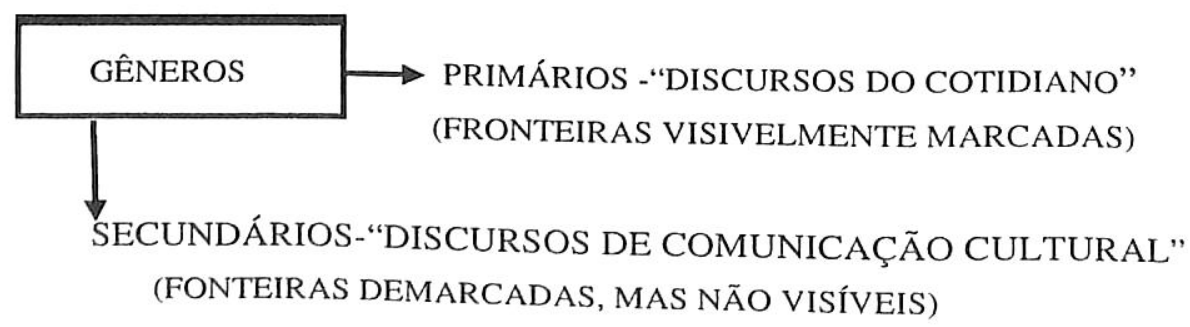

Com isso também se pode ver uma diferença entre enunciados e orações. Segundo Bakhtin (op. cit.), "Comparadas com as fronteiras do enunciado, todas as outras fronteiras (as que delimitam as orações, as combinações de palavras) são apenas relativamente convencionais".

A alternância entre os locutores - que delimita os enunciados - apresenta-se com características diversas e suas relações (de perguntas/respostas, asserção/objeção, afirmação/negação, oferecimento/aceitação, ordem/execução, etc) pressupõem a presença do outro. No entanto, elas não podem ser vistas gramaticalmente, sendo 
isto “ impossível entre as unidades da língua (entre as palavras e orações), tanto no sistema da língua (eixo vertical), quanto no interior do enunciado (eixo horizontal)"(op. cit.). Portanto, a oração difere do enunciado (unidade de comunicação verbal) por ser um unidade da língua. Mas a relação própria do diálogo é apenas uma variante da que especifica o processo da comunicação. Dessa forma, as diferenças entre enunciado e oração resumem-se assim:

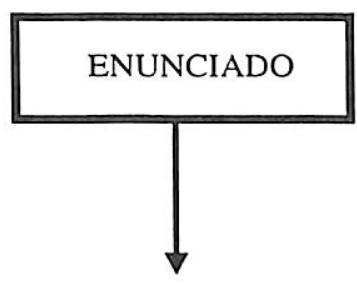

UNIDADE DO

DISCURSO

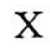

UNIDADE DA

LÍNGUA

Como vimos, ela (a relação dialógica) somente pode ter lugar entre os enunciados de diferentes sujeitos falantes, portanto não pode prescindir do outro e da relação de sentido entre suas falas. E, embora esses fenômenos possam se mostrar marcadamente no diálogo (gênero primário e simples do discurso) eles também se fazem presentes nos gêneros secundários.

A visão bakhtiniana de enunciado - que o coloca como materialidade lingüística e como contexto enunciativo - leva-nos a uma aproximação entre a concepção de texto na $\mathrm{AD}$, como unidade significativa, como tecido organizado e estruturado, dependente do contexto sócio-histórico. Ou seja, do mesmo modo que Bakhtin aponta dentro de um enunciado as relações gramaticalizadas entre as unidades da língua e as relações de sentido entre os enunciados, o texto, na perspectiva do discurso, também se constitui pelas relações internas (da língua) e pelas relações externas (o sentido histórica e ideologicamente constituído no discurso). Assim, podemos pensar que o enunciado está para o texto, como a enunciação está para o discurso. Bakhtin reafirma aqui o diálogo como constitutivo da linguagem. São as relações que se estabelecem entre as réplicas do diálogo que não podem ser verificadas entre palavras e orações, ou seja, dentro do próprio enunciado; elas (as relações) atestam não somente os limites, mas também o elo de ligação entre os enunciados completos que 
ocorrem num processo de comunicação verbal, provenientes de diferentes sujeitos falantes.

A presença do outro é, então, em Bakhtin, parte constitutiva do sentido, como outra voz que habita o sujeito e seu discurso. O conceito da natureza dialógica da linguagem constitui um repensar e uma desconstrução que Bakhtin empreende contrapondo-se ao formalismo e ao ideologismo, concluindo que é o fenômeno social da interação verbal que constitui a verdadeira substância da língua e não um sistema abstrato de formas lingüísticas, uma enunciação monológica isolada ou um ato psicofisiológico de sua produção. Bakhtin, ao afirmar ser a enunciação de natureza social, determina, como objeto da lingüística, a linguagem como interação verbal e não como ato individual e o papel do outro na constituição do sentido. Como conseqüência desse pensamento, tem-se a introdução de sujeito e contexto historicamente constituídos.

A exterioridade materializada na consciência aponta para um sujeito polifônico, lugar de concentração e substituição de vozes já existentes, pelo fato de que, para esse autor, toda palavra traz em si uma outra voz. Polifonia e romance polifônico são termos cunhados por Bakhtin, no intuito de caracterizar alguns romances, a exemplo da obra de Dostoiévski. Ele vê, entre os personagens criados por este romancista, uma relação dialógica de vozes opostas, que se exprimem sem que nenhuma seja dominante. O herói, em Dostoiévski, tem autonomia ideológica e filosófica, é capaz de discordar e rebelar-se contra o autor. Sua voz se coloca ao lado da voz do autor e de outros personagens ou mesmo de heróis de outros romances, como participantes de um diálogo maior, em situação de igualdade entre eles. A isto Bakhtin chama de "autêntica polifonia de vozes plenivalentes" e "multiplicidade de consciêricias eqüipolentes" Assim, para Bakhtin, Dostoiévski é o "criador do romance polifônico" porque "suas obras marcam o surgimento de um herói cuja voz se estrutura do mesmo modo como se estrutura a voz do próprio autor no romance comum" (BAKHTIN, 1997, p.5).Com isso, o pensador russo aplica o princípio dialógico à autoria dos textos, apontando personagens numa relação dialógica de vozes opostas. No caso, a obra de Dostoiévski mostra que os pontos de vista do autor se articulam, pela linguagem, com os pontos de vista expressos pelos personagens. 
É um novo conceito de que inexiste obra acabada, hermeticamente fechada, mas, ao contrário, sempre dando lugar a (re)leituras, ao sentido construído pelo leitor, ao contexto como um entrelaçamente de textos que dialogam entre si, de modo conflitante ou consensual.

Com base em Bakhtin têm lugar novos estudos lingüísticos sobre enunciados, nos quais várias vozes são percebidas simultaneamente, pondo em questão a unicidade do sujeito falante. No entanto, o termo polifonia não pode ser confundido com dialogismo, embora não se possa separá-los, até mesmo porque Bakhtin, em seus escritos, muitas vezes utiliza-os como sinônimos. O último (dialogismo) diz respeito ao princípio constitutivo da linguagem e de todo discurso. A polifonia pode ser vista em certos tipos de textos que deixam entrever outras vozes, opondo-se a textos monofônicos. Ou seja, os textos podem ser monofônicos, onde as vozes se ocultam, dando a impressão de existir apenas uma única voz, ou polifônicos onde as vozes se mostram. Entretanto, serão sempre dialógicos, como resultado de vozes que se cruzam e, assim, os constituem. O efeito de polifonia acionado em alguns discursos deixa escutar as diferentes vozes, sem mascará-las.

Bakhtin partiu da literatura pelo fato de que esta é uma tipologia textual em que o entrelaçamento de vozes é mais visível, diferentemente do discurso autoritário - de verdade única e inconstestável - em que as vozes são camufladas, para que os conflitos também o sejam.

Antes de observarmos tais questões a partir de alguns textos aqui analisados, tentaremos estabelecer uma distinção entre dialogismo, polifonia e intertextualidade:

Depois do termo cunhado e pensado por Bakhtin, a AD recorre ac dialogismo para referir-se a uma dimensão profundamente interativa da linguagem. Como já dissemos, toda enunciação é um elo na cadeia da fala, estabelecendo um prolongamento das que a precederam e é a polêmica constituinte da interação que provoca reações ativas de compreensão, pondo em cena diferentes vozes.

Essas diferentes vozes, vistas por Bakhtin nos romances, na observação de que várias se exprimem, sem que nenhuma seja dominante, põem em questão o sujeito e podem ser vistas sob a ampla 
perspectiva da heterogeneidade discursiva. Dialogismo e polifonia, voltamos a dizer, são termos muitas vezes confundidos e de difícil distinção. No entanto, aos poucos tal distinção se tornou mais clara, empregando-se dialogismo como constitutivo de qualquer manifestação de linguagem - muitas vozes caracterizadas como monofônicas, mas que, na verdade escondem os diálogos que as constituem - e polifonia para qualificar situações em que se deixam entrever várias vozes. Em outras palavras, o diálogo é condição da linguagem e do discurso, não existe linguagem sem que se dê o fenômeno do dialogismo; polifonia é um efeito de sentido produzido em um discurso que não esconde todas as vozes. É a luta entre as vozes sociais que aparece, ou não, mas que está presente em qualquer texto, seja ele considerado monofônico ou polifônico. Em resumo,

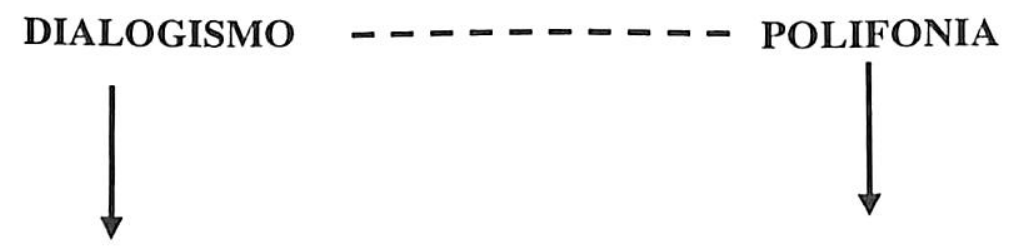

- CONSTITUTIVO DO SENTIDO

-TEXTOS MONOFÔNICOS

OU POLIFÔNICOS

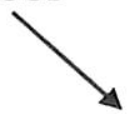

-VOZES À MOSTRA

-TEXTOS POLIFÔNICOS

\section{SEMPRE DIALÓGICOS}

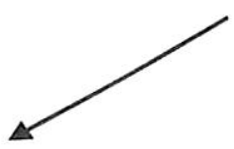

Vejamos os textos publicitários abaixo, no que diz respeito à presença de vozes:

Para cada empresa que morre naturalmente, várias se suicidam. Fazem isso restringindo os investimentos a fábricas, instalações e distribuição, sem perceber que o segredo da sua sobrevivência está em outro lugar: na mente de cada consumidor. Setores que vêm diminuindo investimentos em comunicação perderam vendas ou, simplesmente, não crescem há anos. Já categorias que estão anunciando mais, como a de automóveis e de telefonia, tiveram grande crescimento de mercado. Quem não fortalece sua marca está 
facilitando o trabalho de seus piores concorrentes. E, a médio prazo, destruindo seu próprio negócio. Não cometa esse erro: anuncie. Um cochilo de nada com a marca pode significar a morte para a sua empresa.

\author{
NÃO EXISTEM \\ GRANDES \\ EMPRESAS \\ SEM GRANDES \\ MARCAS
}

\author{
PARAR DE \\ ANUNCIAR \\ TAMBÉM \\ GERA VENDAS \\ MUITAS EMPRESAS \\ FORAM VENDIDAS \\ BARATINHO \\ POR CAUSA DISSO
}

ABAP ASSOCIAÇÃO BRASILEIRA DE AGÊNCIAS DE PUBLICIDADE ANER ASSOCIAÇÃO NACIONAL DE EDITORES DE REVISTAS ABERT ASSOCIAÇÃO BRASILEIRA DE EMISSORAS DE RÁDIO E TELEVISÃO

ANJ ASSOCIAÇÃO NACIONAL DE JORNAIS ABTA ASSOCIAÇÃO BRASILEIRA DE TELECOMUNICAÇŌES POR ASSINATURA FENÁPO FEDERAÇÃO NACIONAL DE AGÊNCIAS DE PROPAGANDA CENTRAL DE OUTDOOR

À primeira vista, são textos monofônicos apresentando apenas a voz da publicidade. No entanto, há, de início, um diálogo entre eles, na continuidade do assunto abordado. Escondidas, não visíveis, estão as vozes do sistema capitalista no que se refere ao mercado (competitividade, qualidade, identidade, margem de lucros, crescimento, continuidade). As associações de empresas publicitárias, embora assinem abaixo, não deixam visíveis as vozes que dizem que na verdade anunciar é um ato benfazejo à sobrevivência da publicidade e não das empresas, é um meio de manter a publicidade.

Bakhtin não distinguia dialogismo e intertextualidade, acreditamos que até mesmo porque o conceito de intertextualidade é muito pouco para recobrir o sentido do diálogo em Bakhtin, por se tratar apenas de um processo de inserção dos sentidos de textos outros em um texto, dando lugar a uma possível transformação. Fiorin (1999, p.30) cita um poema de Manuel Bandeira, O Satélite, como exemplo de intertextualidade pela inserção de elementos de um poema de Raimundo Correia, Plenilúnio e a transformação de sentido entre um e outro: 


\section{O Satélite}

Despojada do velho segredo

De melancolia

Não é agora o golfão de sismas

$\mathrm{O}$ astro dos loucos e enamorados

Mas tão somente

Satélite
Plenilúnio

Há tantos olhos nela

Arroubados

No magnetismo do seu fulgor!

Lua dos tristes enamorados

Golfão de sismas

Fascinador.

Fiorin cita ainda Murilo Mendes com o poema homônimo ao de Gonçalves Dias, "Canção do Exílio":

Minha terra tem macieiras da Califórnia

Onde cantam gaturamos de Veneza (Murilo Mendes)

Minha terra tem palmeiras

Onde canta o sabiá.(Gonçalves Dias)

Novamente os sentidos diferem, pois Murilo faz alusão a Gonçalves Dias para ironizar e não para cantar as belezas da pátria.

Retornando ao nosso tema, vejamos como Barros (1999, p.4), esclarece o que é um texto polifônico, com a primeira estrofe da poesia de João Cabral de Melo Neto "Tecendo a Manhã:

Um galo sozinho não tece uma manhã

ele precisará sempre de outros galos.

De um que apanhe esse grito que ele

e o lance a outro; de um outro galo

que apanhe o grito que um galo antes

e o lance a outro; e de outros galos

que como muitos outros galos se cruzem

os fios de sol de seus gritos de galo,

para que a manhã, desde uma teia tênue,

se vá tecendo, entre todos os galos. 
O poema ilustra a visão bakhtiniana de texto: tecido por fios dialógicos de vozes que se completam ou respondem umas às outras". Melhor dizendo, a intertextualidade não é apenas constituinte, mas se põe à mostra, sem nenhum mascaramento.

Maingueneau (2001, p.139) aborda o fenômeno da polifonia como uma "enunciação sobre outra enunciação." O enunciador utilizase de diferentes recursos para indicar que não é o responsável por um enunciado: na citação da fala de alguém (uso das aspas), na modalização que anuncia a fala do outro, no discurso direto fidedigno (discurso direto livre), no discurso indireto, no discurso indireto livre e, acrescenta, ainda, o pastiche, a paródia, a ironia e o provérbio. Este último trazendo as vozes que esse autor denomina "sabedoria das nações", postas no enunciado, e a ironia podendo ser colocada em qualquer enunciado; ela é essencialmente ambígua porque se mantém entre o que é assumido e o que é rejeitado

Vejamos, então, um exemplo de como o enunciador cita a fala de alguém, mas não se coloca como responsável por esta fala:

[...] O que a máquina de guerra dos Estados Unidos é capaz de fazer nessas circunstâncias?

Ouçamos seu comandante-em-chefe, Bush, no discurso de quinta-feira:

"Nossa reação inclui muito mais que ataques isolados. Americanos não devem esperar uma batalha, mas, sim, uma campanha longa, diferente de qualquer outra que nós já vimos" (Veja, 26/09/2001).

O sujeito falante é o jornalista, o enunciatário é o leitor da revista, o momento da enunciação é definido pela data da revista. Mas, dentro dessa enunciação, podemos ver uma outra enunciação, nas palavras do Presidente Bush, como enunciador, tendo como enunciatário o mundo todo e como data da enunciação quinta-feira (o dia em que o discurso foi pronunciado. Assim, o leitor tem à sua disposição um enunciado jornalístico e um enunciado político, pelas presenças marcadas das vozes dos enunciadores 1(o jornalista), o discurso citante e 2 (o presidente Bush), discurso citado. Para Bahktin (1990, p.144), "O discurso citado é o discurso no discurso, a enunciação na enunciação, mas é, ao mesmo tempo, um discurso sobre o discurso, uma enunciação sobre a enunciação". O discurso citado, ainda segundo Bakhtin (op. cit.), é pensado pelo enunciador 
como fora do contexto, trazido como construção autônoma de outro. No entanto, ao ser incorporado ao discurso passa para o contexto narrativo e, embora o enunciador 1 conserve a autonomia de seu conteúdo, submete-o não apenas às regras sintáticas, estilísticas e composicionais, necessárias à sua apreensão, mas, também, à sua posição discursiva.

Uma outra forma de apresentação do discurso citado, segundo Maingueneau, é quando se faz uso da modalização, também indicativa de um discurso sobre outro discurso, da não responsabilidạde do enunciador, a exemplo do que fizemos no parágrafo anterior:

O discurso citado, ainda segundo Bakhtin (op. cit.), é pensado pelo enunciador como fora do contexto, trazido como construção autônoma de outro.

Há, ainda, o uso de verbos que indicam enunciação, os chamados verbos "dicendi":

"É incompreensível que mais de $80 \%$ dos processos em tramitação no STJ e Supremo tenham sido provocados pelos governantes, critica o ministro" (Isto É, 26/09/2001).

No discurso direto, considerado texto polifônico "fraco", além de o autor se isentar - ou melhor, tentar se isentar - da responsabilidade da fala do outro, simula restituir as falas citadas. Dissemos "simula", pois não é possível pensar em inteira fidelidade, desde que a fala citada está sujeita à interpretação do enunciador e está colocada em outro contexto. Pensemos nas entrevistas que a revista Veja traz nas - já conhecidas e esperadas pelo leitor - "páginas amarelas". São textos que apresentam distintamente duas vozes diferentes, mas, além da escolha do entrevistado conforme a assunto a ser abordado, a sua fala, destituída aparentemente da responsabilidade do entrevistador, é dirigida pelas perguntas que este faz, as quais, consequientemente, apontam para o ponto de vista da própria revista.

Há, no ensino de Língua Portuguesa, uma idéia de que o discurso direto pode ser transformado em discurso indireto:

O Presidente Bush declarou: "O desenvolvimento desse conflito é desconhecido, mas seu final é certo. Venceremos”.

O Presidente Bush declarou que o desenvolvimento desse conflito é desconhecido, mas que o seu final é certo, pois vencerão. 
Na verdade, a idéia de transformação automática esbarra na possibilidade de o enunciador recorrer a diversas maneiras de traduzir a fala do outro, porque há uma exigência apenas de expressar o conteúdo e não a fidelidade à fala. A polifonia pode ser vista a partir do verbo escolhido para introduzir o pensamento do outro que diz como o enunciador está interpretando esse pensamento. Vejamos:

Ao tomar posse na presidência do Supremo Tribunal Federal, em maio deste ano, o Ministro Marco Aurélio Mello, um carioca de 55 anos, flamenguista fanático, avisou que não iria tocar fogo na_República. (Leonel Rocha, Revista Isto É, 26/09/2001).

Adiante o autor do texto reproduz falas do. Ministro que tecem críticas ao Estado. Assim, a escolha do verbo avisou_e da expressão tocar fogo na República_são produzidas por Leonel, parece-nos, querendo antecipar uma ressalva de que as críticas do Ministro significam que o mesmo não tem a intenção de se contrapor ao governo federal. No entanto, como o classifica de "flamenguista fanático", o discurso indireto presente aponta para diferentes situações de enunciação polifônica, ou seja, posiciona-se, introduz, por meio dessa expressão, a idéia da impossibilidade de o ministro não se colocar em posição contrária ao governo federal.

Lembremos, então, que Maingueneau ainda chama a atenção para as formas híbridas, às quais a imprensa vem recorrendo modernamente. Ao mesmo tempo em que o jornalista procura eximirse da responsabilidade da fala do entrevistado, ainda que externando um comentário pessoal, acaba por denunciar, nesse comentário, também o ponto de vista e até as palavras do outro, conforme o texto de Leonel (acima citado).

O discurso indireto livre é considerado por Maingueneau "o tipo mais clássico de hibridismo" porque ele contém os recursos dos dois tipos anteriores, sem distinguir claramente as vozes, sem a absorção de uma voz pela outra, deixando ao leitor uma fronteira muito mal delineada entre as palavras do citando e do citado:

Foi levantar o testo, recebeu na cara vermelha uma baforada de vapor. Não é que ia deixando a comida esturrar? Pôs água nela e remexeu-a com a quenga preta de coco. Em seguida provou o caldo. Insosso, nem parecia bóia de cristão. Chegou-se ao jirau onde se 
guardavam cumbucos e mantas de carne, abriu a mochila de sal, tirou um punhado, jogou-o na panela (Graciliano Ramos, Vidas Secas, 1985, p.42).

A passagem de uma fala para a outra pode ser vista pelo contexto evocado pelo autor na fala de uma mulher sertaneja, do mesmo modo que no percurso do romance vai introduzir falas sem estabelecer as fronteiras.

Esses são textos polifônicos que tratam de discursos relatados. No entanto, existem outros tipos de textos em que a polifonia é menos visível, como provérbios e "slogans", estes últimos muito vistos na propaganda.

O provérbio, por meio do enunciador, faz com que seja ouvida uma voz anônima, a voz de uma sabedoria popular, relativa a determinada cultura:

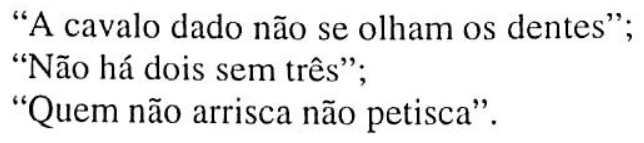

"A cavalo dado não se olham os dentes";

"Não há dois sem três";

"Quem não arrisca não petisca".

A fonte desses enunciados não precisa ser identificada pelo enunciador, por se tratar de um conjunto de enunciados reconhecidos pelos falantes de uma mesma comunidade lingüística, pela sua estrutura, pelo seu tom sentencioso, por não se ancorarem numa situação enunciativa particular, mas generalizada.

O "slogan", com uma estrutura semelhante à do provérbio, não é também da responsabilidade do enunciador que o apresenta como citação, sem explicitar a fonte. No entanto, enquanto o provérbio quer falar de como se procede, o slogan tenta sugestionar um potencial consumidor da validade da marca apresentada; enquanto o provérbio mantém-se estável através dos tempos, o slogan sofre influência das transformações da mídia:

\footnotetext{
"Citroën C-5, um carro como os outros vão ser";

"Maná, adubando dá";

"Pessoas especiais merecem destaque. Destaque no que fazem; destaque no que dizem; destaque no que escolhem. Cliente Bank Boston, apenas uma conseqüência".
} 
Há algum tempo, foi veiculada uma propaganda da Embratel que recorria à sabedoria popular para falar de tarifas reduzidas, como algo impossível de ser visto, utilizando-se de asserções cristalizadas na sociedade: alguém com a foto da sogra na carteira, jóquei gordo, cabeça de bacalhau, etc. Há, então, na propaganda, a presença de vozes do enunciador, do enunciatário, do povo em geral.

A ironia é considerada por Maingueneau como um texto polifônico em que o enunciador se responsabiliza pelas palavras, mas não pelo ponto de vista que o enunciado defende, pois ele "subverte" sua própria fala. $\mathrm{O}$ enunciador age como se estivesse representando um personagem ridículo, deixando que sua distância dessas palavras seja vista pela entonação, pela mímica, pelo contexto. De maneira diversa do provérbio que é usado como verdade constatada através dos tempos para validar uma situação, a ironia é um enunciado que, apesar de pronunciado, invalida seu conteúdo.

Resumindo, Maingueneau considera

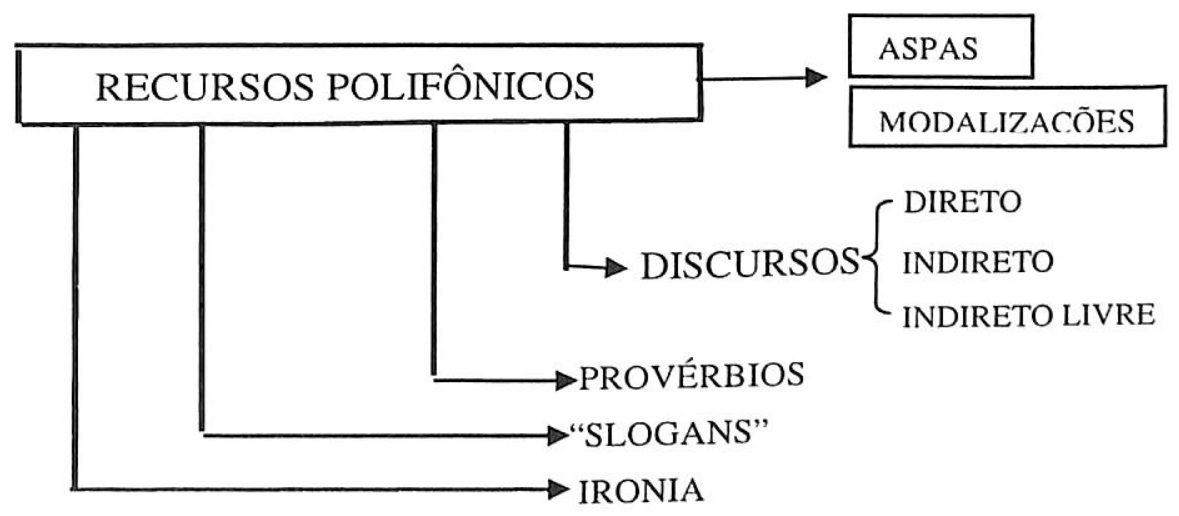

É com esses tipos de fenômenos que Maingueneau (op.cit) introduz na linguiística os estudos polifônicos de Bakhtin, isto é, da literatura romanesca para o enunciado. Os textos polifônicos são construídos com a responsabilidade de transmitir as próprias idéias e palavras, bem como as idéias e palavras do outro, abandonando o autoritarismo da fala monológica, ao mesmo tempo em que, ao recuperar a fala alheia, deixa de assumir o que quer dizer porque o faz através de outra(s) voz(es). 
Bakhtin traz, então para a AD uma contribuição, estabelecida pela mudança de paradigma nos estudos da linguagem, mudança esta não concluída por se tratar de uma visão de discurso dialogicamente constituído, ou seja, o próprio paradigma está sempre sujeito a mudanças. Para Brait (2001, p.28), "Ao apontar [também] para um 'contexto mais amplo', Bakhtin já acena com a participação do interdiscurso, ou seja, da história e da memória, nem sempre explícitas na situação, mas sem dúvida participantes da produção de sentidos". Isto mostra que o conceito de interação bakhtiniano difere do de outras teorias interacionistas que restringem a análise à situação imediata para compreensão dos sentidos.

Assim as formulações teóricas dos analistas do discurso, com início em Bakhtin, têm bases assentadas no princípio dialógico e na polifonia. As ciências humanas voltam-se para o homem como produtor de discursos ideologicamente (contexto histórico, social, cultural) constituídos, por isso essencialmente dialógicos. O dialogismo e a polifonia são, pois, questões de suma importância para os que vêem o diálogo como condição da linguagem e do discurso, embora haja textos monofônicos e polifônicos, de acordo com o processo discursivo empregado.

Sabemos, no entanto, que muito ainda se pode fazer na descrição e análise de polifonia ou monofonia de textos e discursos sem esquecermos que estes são diferentes efeitos de sentido e que os textos monofônicos escondem os diálogos deixados à mostra nos textos polifônicos, sob a aparência de uma única voz.

Desse modo, fica bem evidente que Bakhtin inaugura uma nova perspectiva dos estudos da linguagem, ao pensá-la em constante movimento, inacabada, dependente de uma relação dialógica que acontece entre enunciados de diferentes sujeitos falantes - (o outro), como parte constitutiva do sujeito e do sentido. São as outras "vozes" presentes no enunciado que apontam para o diálogo como constitutivo da linguagem e do discurso, deixando-se ver pela polifonia ou mascarando-se no fenômeno do dialogismo. Essa é, então, uma visão de sujeito produtor de discursos ideologicamente constituídos, que antecipa a participação da história e da memória na produção de sentidos.

Portanto, podemos constatar algumas contribuições de Bakhtin aos estudos do discurso, tais como: 
$>$ O signo concebido como dialético, dinâmico, plurivalente;

$>$ O caráter social da enunciação;

$>$ Os princípios da dialogia e da polifonia;

$>$ O discurso dialogicamente constituído;

$>$ Aceno para a história e para a memória como participantes da produção de sentido.

Referências

BAKHTIN, Mikhail. Marxismo e Filosofia da Linguagem. São Paulo: Hucitec, 1990.

BAKHTIN, Mikhail. Estética da Criação Verbal. São Paulo: Martins Fontes 1992.

BAKHTIN, Mikhail. Problemas da Poética de Dostoievski. Rio de Janeiro: Forense Universitária, 1997.

BARROS, Diana Luz Pessoa de. Contribuições de Bakhtin às Teorias do Discurso. In: BRAITH, Beth (org.). Bakhtin, Dialogismo e Construção do Sentido. São Paulo: Unicamp, 1997.

BARROS, Diana Luz Pessoa de e FIORIN, José Luiz (orgs.) Dialogismo, Polifonia, Intertextualidade, São Paulo, EDUSP, 1999.

BRAIT, Beth. O Discurso sob o Olhar de Bakhtin. In: GREGOLIN, Maria do Rosário (org.). Análise do Discurso: as materialidades do sentido. São Paulo: Claraluz, 2001.

DUCROT, Oswald. O Dizer e o Dito. São Paulo, Pontes, 1987.

JOBIM E SOUZA, Solange. Mikhail Bakhtin e Walter Benjamin: Polifonia, alegoria, conceito de verdade no discurso da ciência contemporânea.In: BRAITH, Beth (org.). Bakhtin, Dialogismo $e$ Construção do Sentido. São Paulo: Unicamp, 1997.

MAINGUENEAU, Dominique. Les Termes de l'Analyse du Discours. Paris, França, Seuil, 1996.

MAINGUENEAU, Dominique. Análise de Textos de Comunicação. São Paulo, Cortez, 2001. 